\title{
O Livro dos Mártires de Bernardo de Brihuega: dois séculos de leitura em português
}

\author{
Cristina Sobral \\ Universidade de Lisboa (FLUL/CLUL) (Portugal) \\ csobral@campus.ul.pt \\ http://orcid.org/0000-0002-0097-3959 \\ Esperança Cardeira \\ Universidade de Lisboa (FLUL/CLUL) (Portugal) \\ ecardeira@campus.ul.pt
}

Recibido o 17/02/2018

Aceptado o 07/05/2018

\section{Resumo}

Na sequência da edição semidiplomática do Liuro $e$ legẽda que fala de todolos feytos e payxoões dos sãtos martires em lingoagem portugues (Lisboa, João Pedro Bonhomini de Cremona, 1513, Bitagap texid 1032), analisa-se neste artigo o estado de língua mais antigo que o testemunho atesta. Confirmando, com o levantamento de castelhanismos, que se trata de um texto traduzido para português a partir do castelhano, apuram-se dados linguísticos que permitem datar a tradução do início do séc. XIV (reinado de D. Dinis), na mesma época em que foi traduzido o segundo livro da compilação briocana (Vidas e Paixões dos Apóstolos, Bitagap texid 1044).

\section{Palabras chave}

Bernardo de Brihuega; tradução; hagiografia; português medieval; história do português

\section{Sumario}

1. Introdução. 2. Castelhanismos. 3. Representação da nasalidade. 4. Síncope do -d-intervocálico e resolução do hiato. 5. Determinantes possessivos. 6. Particípio passado da $2^{\text {a }}$ conjugação. 7. Terminações nasais. 8. Género dos nomes. 9. Demonstrativos: formas reforçadas. 10. Outros indicadores. 11. Conclusões.

\section{Bernardo de Brihuega's Livro dos Mártires: two centuries} of reading in Portuguese

Following the semidiplomatic edition of Liuro e legẽda que fala de todolos feytos e payxoões dos sãtos martires em lingoagem portugues (Lisbon, João Pedro Bonhomini de Cremona, 1513, Bitagap texid 1032), this article analyzes the state of the Portuguese language attested in the material. Confirming, with the survey of Castilianisms, that it is a text translated from Castilian into Portuguese, we find linguistic data that allow us to date the translation to the beginning of the fourteenth century (during the reign of D. Dinis), at the same time when the second book of Brihuega's compilation (Vidas e Paixões dos Apóstolos, Bitagap texid 1044) was translated.

\section{Keywords}

Bernardo de Brihuega; translation; hagiography; medieval Portuguese; history of Portuguese

\section{Contents}

1. Introduction. 2. Castilianisms. 3. Representation of nasality. 4. Syncope of intervocalic - $d$ - and hiatus solution. 5. Possessive determiners. 6. Past participle of the $2^{\text {nd }}$ conjugation. 7. Nasal endings. 8 . Gender of the names. 9. Demonstratives: reinforced forms. 10. Other indicators. 11. Conclusions. 


\section{INTRODUÇÃo}

Bernardo de Brihuega é um dos menos conhecidos autores da Idade Média peninsular, certamente porque da sua obra sobreviveram poucos testemunhos na língua original (o castelhano). Já em 1887 Rudolfo Beer chama a atenção para os "cinco libros que compiló Bernardo de Brihuega por orden del rey don Alfonso el Sabio". O conhecimento do autor recebe decisivos contributos de Manuel C. Díaz y Díaz (1962), Mário Martins (1961, 1980a e 1980b), Isabel Cepeda (1982-89 e 1993) e Francisco Bautista (2014 e 2015). O seu estado atual pode ser resumido como se segue.

Bernardo de Brihuega, cónego da igreja de Sevilha, foi encarregado por Afonso X da redação de uma obra que, sob o título Genesi Alfonsii, contava em cinco livros a história da Salvação e dos seus protagonistas a partir do Novo Testamento: 1) vida de Jesus e de Santa Maria, 2) vidas e paixões dos apóstolos, 3) paixões dos mártires, 4) vidas dos confessores e 5) vidas das virgens. 0 trabalho começou pela recolha, em latim, das fontes hagiográficas de que Bernardo pôde dispor percorrendo, em mais do que uma viagem, os mosteiros de Espanha. O resultado parcial desta recolha conserva-se nos códices 2538 a 2541 (final do séc. XIV ou primeira metade do XV) da Biblioteca da Universidade de Salamanca (Martins 1980a: 127 e Martins 1980b). Mas o projeto devia ir mais além: tratava-se de redigir as biografias em castelhano, confrontando e combinando fontes, apurando o estilo, dando à obra coerência historiográfica.

Até recentemente julgava-se que desta redação em castelhano nada restava e que ela podia ser conhecida apenas indiretamente a partir das traduções para português do segundo (Vidas e Paixões dos Apóstolos, Bitagap texid 1044) e do terceiro (Liuro e legẽda que fala de todolos feytos e payxoões dos sãtos martires em lingoagem portugues, Lisboa, João Pedro Bonhomini de Cremona, 1513, Bitagap texid 1032) livros da série. Estudos recentes (Bautista 2015) revelaram a sobrevivência parcial do primeiro livro em castelhano (ms. 11-144 da Biblioteca Zabálburu, Madrid) e de uma versão parcial de uma primitiva redação em castelhano do segundo livro (ms. 10252 da BNEspanha), versão essa anterior à versão final que terá sido traduzida nas portuguesas Vidas e paixões dos apóstolos (Bautista 2014: 93 e segs.). A dependência de um texto em castelhano foi demonstrada por Cepeda (Cepeda 1982-89, I: xxiii; cf. Bautista 2014).

Quanto ao terceiro livro, está por determinar se algumas das paixões dos mártires do ms. 10252 provêm da versão castelhana, visto que F. Bautista não pôde dispor de "ejemplares romances que puedan servir de término de comparación" (Bautista 2014: 100). De facto, o acesso ao texto do exemplar único do pos-incunábulo de 1513 (Vila Viçosa, Biblioteca da Casa de Bragança, 36; BiTAGAP Manid 1028, cnum 1037) não era, até agora, fácil. Em 1993, Isabel Cepeda dispunha de uma fotocópia deste texto, obtida para o Centro de Linguística da Universidade de Lisboa com a finalidade de preparar uma edição crítica, na sequência da edição crítica das Vidas e Paixões dos Apóstolos (Cepeda 1982-1989). Tal edição não chegou a concretizar-se, permanecendo, portanto, o texto inacessível à generalidade dos investigadores. Em 1993 foi confrontado com um fragmento manuscrito entretanto identificado na Torre do Tombo (IANTT, Fragmentos. Caixa 20, n. 10; Bitagap Manid 1750, cnum 8977; Cepeda 1993).

Já em 1980 M. Martins observara que, no Livro dos Mártires, "a linguagem [...] não é posterior ao tempo do rei D. Duarte" (Martins 1980a: 129) e interrogava-se se não teriam sobrevivido manuscritos da versão portuguesa, lembrando que a livraria de D. Duarte possuía um "Livro dos Martyres" (1980a: 128-129)' que poderia talvez ser o terceiro livro da compilação briocana. A identificação do fragmento por Cepeda veio, de facto, comprovar a existência de um testemunho manuscrito do séc. XV, num códice em português, de grandes dimensões ( $440 \times 290 \mathrm{~mm}$ ) e cuidadosamente decorado com letrinas de três linhas, preenchidas a cheio, vermelho e azul, alternadamente, e filigranadas, com chicotes prolongando-se pelas margens, com caldeirões a azul e citações latinas rubricadas.

Confrontado o texto (apenas as duas páginas interiores do fólio usado como capa de livro notarial foram legíveis) com o testemunho impresso, Cepeda (1993: 511) constatou 1) que este

"Veja-se a referência a um "Livro dos Martyres" entre os "livros de lingoajem" da livraria de D. Duarte, (Livro dos conselhos de el-rei D. Duarte (livro da cartuxa), p. 207). 
apresenta diversos erros de composição ausentes do manuscrito e que 2) o manuscrito apresenta variantes linguísticas mais antigas do que as do pos-incunábulo (regista as formas meor) menor, caudees/caudes, enna/em a, ventuyra/ventura, de sũu/de sum, aa(s)/as, deziam/diziam, fezeron/fizerom). Datando do séc. XV o códice a que pertencia o fólio desmembrado, a autora refere-se à data da tradução do texto nele copiado por analogia com a datação no final do reinado de D. Dinis que atribuira à tradução das Vidas e paixões dos apóstolos (Cepeda 1982-1989, I: xli): "a exemplo do que aconteceu com As vidas e paixões dos Apóstolos, terá sido traduzido do casteIhano na época de D. Dinis" (Cepeda 1993: 508).

Neste artigo propomo-nos rever a questão da datação do estado da língua atestado no Livro dos Mártires de 1513.

Atualmente, encontramos novas condições para estudar de forma mais consistente o estado da língua do texto do Livro dos Mártires de 1513. Foi editado semidiplomaticamente e disponibilizado no Corpus de Textos Antigos (Sonsino, Cruz e Sobral), base de dados que oferece, em modo pesquisável, edições semidiplomáticas de textos indexados à BITAGAP (http://alfclul.clul. ul.pt/teitok/cta/index.php?action=home). É agora possível fazer pesquisas sistemáticas de formas e obter dados estatísticos fiáveis que suportem conclusões fundamentadas acerca da data da tradução. Por outro lado, a disponibilização de outros textos na mesma base de dados permite agora realizar pertinentes comparações de dados. Para publicação em breve, encontram-se já transcritos ambos os testemunhos do Orto do Esposo (BITAGAP Texid 1082), texto escrito no final do séc. XIV ou nas primeiras décadas do XV, bem como o texto do Flos Sanctorum de 1513 (BItAGAP Texid 1028), traduzido entre 1511 e 1513. Assim, será possível a comparação do estado da língua atestado no Livro dos Mártires com os dados linguísticos destes dois outros textos que documentam a língua, respetivamente, no final do séc. XIV e no início do séc. XVI. Melhor: a língua atestada no Flos Sanctorum fornecerá a imagem do que poderemos esperar do estado da língua do Livro dos Mártires se a tradução for coeva da impressão.

Estamos, de facto, perante duas obras, o Livro dos Mártires e o Flos Sanctorum, que parecem ter feito parte de um mesmo programa editorial. Impressos no mesmo ano, com escassos cinco meses de distância (O Flos Sanctorum acabou de se imprimir a 15 de março e o Livro dos Mártires a 17 de agosto), os dois impressores responsáveis, João Pedro Bonhomini de Cremona e Hermão de Campos, foram sócios de Valentim Fernandes nas primeiras décadas de quinhentos. Fundando-se na observação do material tipográfico e xilográfico, J. J. Alves Dias defende que Bonhomini e Campos foram, com Nicolau Gazini, impressores a quem Valentim Fernandes deu sociedade na sua oficina, estabelecida em Lisboa desde o século anterior (Dias 1995: 25). Com Valentim Fernandes assinaram trabalhos conjuntos e com ele partilharam os materiais disponíveis. Uma posterior análise mais detalhada (Jüsten 2006: 78) confirma a conclusão avançada por Dias $^{2}$. Ambos os impressos parecem ter tido um papel determinante nas relações estabelecidas pelos evangelizadores portugueses com o Negus da Etiópia (Martins 1961) e, se considerarmos que ambos beneficiaram de privilégio de D. Manuel, é lícito supor que parte da tiragem esteve desde o início destinada a servir os desígnios expansionistas do rei português. Mais ainda: ambos os legendários partilham, praticamente sem variantes, os textos preliminares: o prólogo de Fr. Gauberto Fabrício de Vagad, a tradução da Paixão de João Gerson, a Carta de Pôncio Pilatos sobre a morte de Jesus e a Carta de Públio Lêntulo sobre o retrato de Jesus (Sobral 2000: 41-42). É evidente que os dois impressores trabalharam em espaço comum e coordenadamente. Seria de esperar, portanto, que recorressem ao mesmo tradutor ou a tradutores próximos, a menos que de uma das obras a imprimir se dispusesse de um texto já em português, como parece ser o caso do Livro dos Mártires.

\section{Castelhanismos}

A análise do texto revela, antes de mais, numerosos erros de composição, tal como Cepeda havia já notado na colação com o fragmento manuscrito. Apesar da qualidade técnica e estética atri-

${ }^{2}$ Os dois pos-incunábulos partilham uma gravura (gravura HMJ, G. 77-78 A; Jüsten 2006: 416). 
buída ao impressor João Pedro Bonhomini ${ }^{3}$, a identificação apenas de erros evidentes, patentes em agramaticalidade notória, mostra uma média de 1,5 erros por página de texto composto. É possível que o facto de não ser falante nativo da língua em que trabalhava tenha facilitado estes erros e que tenha diminuído a capacidade de autocorreção. Por outro lado, é natural que, ao mesmo tempo, o facto de não compor na sua língua tenha reprimido o natural processo de atualização linguística e tenha propiciado a conservação de formas linguísticas do original de imprensa. Assim sobreviveu uma grande quantidade de castelhanismos, prova irrefutável de que o Livro dos Mártires foi traduzido de um texto em castelhano. Encontram-se:

1. castelhanismos gráficos, como a consoante palatal representada pelo dígrafo Il: 12 ocorrências de marauilloso, marauilla e flexões do verbo marauillar, contra 214 com o dígrafo Ih, e três ocorrências de flexões do verbo semellar, contra $141 \mathrm{com} / \mathrm{h}$; por outro lado, na forma estrelhas (1 ocorrência), o dígrafo Ih atesta a palatalização de -LL-, caraterística do castelhano.

2. formas monotongadas do ditongo ou: ouy (ouvi), soterro (soterrou), mostro (mostrou), locura (loucura), loco (louco), otras (outras), etc.

3. formas verbais: conheçio (conheceu), fiziesse (fizesse), fecho (feito), quijerem (quiserem), abrierõ (abriram), cayerõ (cairam), tẽgo (tenho), falado (hallado, pela correspondência h-/f- como em hijo/filho, higo/figo, hoja/folha, etc.); infinitos verbais da $3^{a}$ conjugação: soffrir (9 ocorrências / sofrer soffrer 52), morir (2 ocorrências / morrer morer 66).

4. outras formas: pequenhos (1 ocorrência), Uerdaderamente (2 ocorrências) su oraçã (1 ocorrência), mas (mais, 3 ocorrências), seruientes, temptaçion, fojas, diffiçiles, merçed (1 ocorrência cada).

5. sintaxe: e trouuerõ no ao anfiteatro para o mataram hay as bestas, construção que parece depender da construção castelhana para que lo mataran.

A identificação de outros possíveis castelhanismos não pode fazer-se sem a consideração de hábitos gráficos do impressor. De facto, formas como payxones (1 ocorrência, minoritária em relação a formas sem - $n$ - intervocálico: payxões, 11 ; paixões, 18; payxoões, 2 ; paixoões, 7), luna (7 ocorrências; lũa, 11; luũa, 1), manos (8 ocorrências; mãos, 43; maãos, 112; mãaos, 1), as formas do artigo indefinido e de pronomes femininos huna, -as (3 ocorrências), vna (6 ocorrências), nemhuna (1 ocorrência), alguna (2 ocorrências) e as formas verbais gejunauã (1 ocorrência), gejunãdo (1 ocorrência) e gejunando (1 ocorrência), que aparecem como castelhanismos pela conservação do - $n$ - intervocálico, podem, na verdade, mais não ser do que formas em que o -n- representa a nasalidade da vogal anterior. Temos casos em que a ambiguidade é notória, como no sintagma nominal jrmano el tribũo: o artigo é claramente castelhano, o que conduz à interpretação do primeiro substantivo como castelhanismo. Já nas duas ocorrências de cano, minoritárias relativamente às formas com terminação nasal (cão, 3; cam, 9; caam, 1; caãa 1), terá necessariamente que ser interpretada como forma portuguesa com ditongo cuja nasalidade é representada pela consoante nasal ${ }^{4}$. Assim, do mesmo modo, a abreviatura xp̃ana (cristana ou cristãa?) onde poderíamos esperar ditongo na penúltima sílaba se se tratasse de castelhanismo (cristiana). Como representação de nasalidade da vogal anterior explica Machado (1989, s. v. jejum, jejuar) as variantes jajuno e jajunar, que se encontram já no séc. XIV e que classifica como gráficas, o que retira as formas deste verbo acima citadas do grupo dos castelhanismos. Que o compositor do Livro dos Mártires usava os grafemas $<\mathrm{m}, \mathrm{n}>$ para marcar a nasalidade da vogal anterior é inequívoco em formas como coraçaom (coração), huum, Symaon (Symaõ), bona (bõa).

\footnotetext{
3 "carácter homogéneo e [...] esteticamente apurado da produção firmada por João Pedro de Cremona" (Jüsten 2006: 81), "sobriedade com que utiliza o seu material tipográfico de grande apuro estético" (Jüsten 2006: 481).

${ }^{4} \mathrm{~A}$ representação por $<\mathrm{n}>$ da nasalidade da vogal anterior é conhecida em documentos portugueses sobretudo do século XIII e início do XIV (cf. Maia 1986: 577-580; v. também Ferreiro 2008).
} 


\section{RepresentaÇÃo da NASALIDAde}

A alternância entre sinal geral de abreviatura e $<m, n>$ na representação da nasalidade vocálica estende-se à alternância do seu uso na representação de consoantes nasais e, aqui, com consequências na datação do estado da língua. Estabeleça-se, desde logo, sem dúvida, que a seleção, pelo compositor, de um tipo com vogal com til serve como abreviatura da consoante nasal da sílaba seguinte, inclusive quando se trata de formar dígrafo para a representação da consoante palatal. Assim encontramos, por exemplo, as formas tĩha (tinha), hũhas (hunhas), cõpãha (cõpanha), estrãho (estranho), sõhos (sonhos), pũhadas (punhadas). Mas também várias formas em que o til abrevia apenas consoante nasal: quinzẽo (quinzeno), arteĩo (Artemio), jõita (jonita), forã (forma), diacõos (diaconos), dõa (dona), emfẽros (emfermos), tragẽos (trage nos).

Temos, porém, um problema, quando ocorre til em formas que tiveram, no português antigo, hiato resultante de queda de -n- intervocálico latino e que posteriormente desenvolveram segmentos consonânticos para resolução do hiato. Como interpretar e como representar numa edição semidiplomática que anuncia como critério o desenvolvimento de abreviaturas formas como camĩho (4 ocorrências), que coocorre com camĩo (1 ocorrência) e caminho (10 ocorrências)? Do mesmo modo menĩo (2 ocorrências) e menino (com as respetivas flexões em género e número, 108 ocorrências). E ainda pẽas (10 ocorrências) e penas (119 ocorrências)? Estamos perante formas do português antigo que remontam à data da tradução no reinado de $D$. Dinis, variantes linguísticas, ou simplesmente perante representações gráficas da consoante nasal? Note-se que, no último caso, pẽas, teríamos um estado da língua bastante antigo, visto que esta divergente de pena se atesta, segundo Machado (1989: s.v. pena), no séc. XIII e que, no Orto do Esposo (final do séc. XIV/início do XV) ocorre sempre pena, nunca a forma divergente.

Só a prova de que o Livro dos Mártires conserva formas do português antigo que não dependem de interpretação de ambiguidades pode fornecer um fator de ponderação positiva na análise destes casos.

Vejamos as formas do verbo manifestar, cujo registo de ocorrências no Livro dos Mártires se apresenta no Quadro 1.

\begin{tabular}{|l|r|}
\hline \multicolumn{1}{|c|}{ Formas } & \multicolumn{1}{c|}{ oc. } \\
\hline maẽfestado, maẽfesto & 2 \\
\hline meẽfestar, meenfestando, meẽfestassem & 4 \\
\hline $\begin{array}{l}\text { mẽfestar, mẽfestã, mẽfestas, mẽfestamos, menfestamos, mẽfestaua, } \\
\text { mẽfestauã, mẽfestou, mẽfestando, menfestauedes, menfestos }\end{array}$ & 13 \\
\hline Manfestaua & 1 \\
\hline manifesto, manifesta & 2 \\
\hline
\end{tabular}

Quadro 1. Ocorrências de manifestar

A forma moderna com - $n$ - intervocálico encontra-se já no séc. XIV e a forma com hiato maẽfestar é do séc. XIII, prolongando-se o seu uso pelo XIV. Dá lugar, no XV, a uma forma sem hiato menfestar (Machado 1989: s.v. manifestar), que supõe, naturalmente, a crase de uma forma intermédia mẽẽfestar. No Flos Sanctorum não encontramos nenhuma das formas antigas do verbo e sim, sempre, formas modernas e com grafia pseudo-latina: magnifestar. O texto castelhano traduzido no Livro dos Mártires apresentava necessariamente formas com - $n$ - intervocálico ( $m a$ nifestar), tal como se apresentam na Leyenda de los Santos traduzida no Flos Sanctorum (onde têm a mesma grafia pseudo-latina que o tradutor do Flos Sanctorum reproduziu). Não há dúvida, portanto, de que as formas maioritárias no Livro dos Mártires não resultam de influência do texto traduzido e foram conservadas de uma tradução que deve remontar ao séc. XIV, provavelmente transmitida por um manuscrito do séc. XV que fez atualizações linguísticas.

Vejamos o que a este respeito nos dizem os indicadores do português médio. 


\section{SínCOPE DO -D- INTERVOCÁliCO E RESOLUÇÃo dO HIATO}

A síncope do - $d$ - intervocálico no morfema número-pessoal da flexão verbal é, na opinião de Bechara (1991: 70), "o fenômeno balizador por excelência" entre o período arcaico e o arcaico médio. Na franja de separação entre português antigo e médio registam-se esporádicas emergências, nos documentos escritos, de formas sincopadas, testemunhos prováveis de uma alternância, na oralidade, entre formas plenas e sincopadas logo na segunda metade do séc. XIV. A inversão da tendência verifica-se na viragem do primeiro para o segundo quartel do séc. XV, quando as formas plenas se tornam residuais (Cardeira 2005: 175ss). No Flos Sanctorum a variante com conservação de - $d$ - é, de facto, residual, correspondendo apenas a $2 \%$ do total de formas da $2^{\text {a }}$ pessoa do plural. Note-se que $40 \%$ das formas sincopadas apresentam, já, evidências de ditongação ${ }^{5}$ e que a síncope se regista, até, no presente do verbo ir (hijs, em alternância com hydes). São dados muito semelhantes aos do Cancioneiro Geral de Garcia de Resende, impresso em 1516 e que compila textos da segunda metade do séc. XV (Cardeira 2013: 583). Esperaríamos encontrar resultados semelhantes também no Livro dos Mártires de 1513. Mas não: aqui a conservação de - $d$ - é claramente maioritária e as formas sincopadas representam apenas $8.7 \%$ do total ${ }^{6}$. Se lembrarmos que no Leal Conselheiro a variante sincopada é bastante mais frequente do que a forma plena (Vasconcellos 1906: 176) ${ }^{7}$ teremos que situar o Livro dos Mártires em época anterior a 1438. De facto, a baixa frequência de síncope no morfema da $2^{a}$ pessoa do plural no Livro do Mártires coloca-o em época muito próxima do Orto do Esposo (final do séc. XIV, início do $\mathrm{XV}$ ), em que não se regista a variante sincopada (Quadro 2).

\begin{tabular}{|l|l|}
\hline \multicolumn{1}{|c|}{ Texto } & \multicolumn{1}{c|}{ Perc. } \\
\hline Orto do Esposo (XIV-XV) & $100 \%$ \\
\hline Livro dos Mártires & $91.3 \%$ \\
\hline Leal Conselheiro (1438) & residual \\
\hline Flos Sanctorum (1513) & residual (2\%) \\
\hline Cancioneiro Geral (1516) & residual \\
\hline
\end{tabular}

Quadro 2. Presença de - $d$ - no morfema número-pessoal

Note-se, no entanto, que em $50 \%$ das formas sincopadas do Livro dos Mártires, o ditongo está já expresso na representação gráfica, por $\langle i\rangle$ ou $\langle y\rangle$, da semivogal. Assim, por exemplo, seredes alterna com serees e sereis, sereys. Estas formas ditongadas devem ser, portanto, testemunhos da atualização linguística do pos-incunábulo, enquanto as formas plenas espelham o estado de língua do manuscrito que lhe serviu de base.

O mesmo raciocínio se pode aplicar ao plural das formas terminadas em -vil/-vel. No português antigo existia alternância entre palavras paroxítonas terminadas em -vil (<-BïLE) e em -vel (<-BĬLE); decorrente do singular, o plural destas formas apresentava oscilação em -viis, -vis ou -vees, -veis, -ves, com hiato ou ditongação ou crase como solução para a terminação hiática. Na primeira metade do séc. XV a terminação -vel torna-se mais frequente do que -vil e o plural começa a registar representação explícita do ditongo, nomeadamente em textos de caráter literário (Cardeira 2005: 239-241). Enquanto no Orto do Esposo o plural -uees ainda alterna com -uijs, no Livro dos Mártires já encontramos os plurais -vees, -ves em variação com -veis, o que aponta, de novo, para um processo de atualização linguística.

\footnotetext{
${ }^{5} 10$ formas plenas, 447 sincopadas; destas, 178 têm representação explícita da semivogal ( $\left.\left.<\mathrm{i}, \mathrm{j}, \mathrm{y}\right\rangle\right)$.

${ }^{6} 596$ formas plenas, 57 sincopadas; destas, 28 com representação explícita da semivogal.

${ }^{7}$ Leite de Vasconcellos nota que as formas plenas se encontram, quase exclusivamente, em transcrições de textos mais antigos.
} 


\section{Determinantes possessivos}

Também não se registam as formas átonas dos possessivos que ocorrem ainda em textos do séc. XV. No português antigo desenvolveram-se como proclíticas as formas $m a$, $t a$, sa, ao lado das tónicas minha (ou mĩa), tua e sua, embora a distinção entre átonas e tónicas nem sempre fosse observada. O uso de formas absolutas em função adjetiva começa a registar-se ainda na segunda metade do séc. XIII: minha, tua e sua ocorrem já com função de determinante quer em documentos galegos quer em portugueses a partir de meados desse século. Trata-se, contudo, de ocorrências esporádicas, uma vez que a inversão da tendência se verificará apenas na viragem do séc. XIV para o XV (Cardeira 2005: 247ss). O desaparecimento das formas átonas parece ter sido um processo lento que se prolongou por todo o séc. XV: ainda encontramos ta e sa(s) no Livro dos Conselhos de D. Duarte (1423-1438) e no Cancioneiro Geral de Garcia de Resende (Cardeira 2013: 585). A ausência de formas átonas no Livro dos Mártires afigura-se, portanto, significativa, na medida em que sugere um procedimento de atualização linguística no momento da impressão do pos-incunábulo.

\section{Particípio passado da $2^{a}$ conjugação}

Outra das mudanças ocorridas durante o português médio foi a substituição da terminação do particípio passado da $2^{a}$ conjugação, -udo, por -ido. As duas terminações estiveram em variação durante todo o séc. XIV mas no início do séc. XV a variante -ido é selecionada e-udo passa a ocorrer somente em determinadas fórmulas petrificadas, mais frequentes em documentos de tipo notarial do que em textos literários, como é o caso do particípio teudo. A inversão da tendência verifica-se no início do segundo quartel do séc. $\mathrm{XV}$, seguindo-se um período em que os antigos particípios se tornam residuais (Cardeira 2005: 203ss).

O processo de substituição de -udo por -ido pode considerar-se completo no início do séc. XVI: no Cancioneiro Geral já só encontramos o novo particípio, com apenas uma exceção, que se justifica por necessidade rimática (sofruda, em rima com acuda, Cardeira 2013: 585). Panorama semelhante é o que encontramos no Flos Sanctorum, que tem apenas 4 particípios em -udo, todos do verbo ter e derivados ${ }^{8}$, e 280 particípios em -ido. No Livro dos Mártires, por outro lado, os particípios em -udo representam $9.5 \%$ do total ${ }^{9}$. Trata-se de uma percentagem que se aproxima bastante daquela encontrada no Leal Conselheiro, 7.8\% (Cambraia 2003: 59), mas que se afasta, já, da registada no Orto do Esposo (38\%). Como a versão C dos Diálogos de S. Gregório, de 1416, apresenta $17.7 \%$ de particípios em -udo (Cambraia 2003: 59), podemos colocar o Livro dos Mártires entre 1416 e 1438 (v. Quadro 3).

\begin{tabular}{|l|l|}
\hline \multicolumn{1}{|c|}{ Texto } & \multicolumn{1}{c|}{ Perc. } \\
\hline Orto do Esposo (XIV-XV) & $38 \%$ \\
\hline Diálogos de S. Gregório (1416) & $17.7 \%$ \\
\hline Livro dos Mártires & $9.5 \%$ \\
\hline Leal Conselheiro (1438) & $7.8 \%$ \\
\hline Flos Sanctorum (1513) & residual (1.4\%) \\
\hline Cancioneiro Geral (1516) & residual \\
\hline
\end{tabular}

Quadro 3. Presença de particípios passados em -udo

\footnotetext{
${ }^{8}$ Ocorre ainda um NP, vestígio de um antigo particípio em -udo, Dõ Reçebudo.

${ }^{9}$ Eis os valores absolutos: 47 particípios em -udo, 447 em -ido. Note-se que os particípios antigos não são, aqui, exclusivos do verbo ter (e derivados); por exemplo, o verbo vencer conta com 19 particípios em -udo e 40 em -ido.
} 


\section{TERMinaÇÕES NASAIS}

De várias terminações latinas resultaram, em português, três terminações: -ão, -ã e -õ, que acabaram por convergir no ditongo -ão. Assim, formas nominais como mão, cão, leã, multidão e verbais como amam ou são, bem como palavras gramaticais como tão e não, tiveram, no português antigo, terminações que correspondiam à etimologia: mão <MANU-, cã <CANE-, leõ <LEONE-, multidõe <MULTITUDINE-; amam <AMANT, sõ <SUNT; tã <TAM, nõ <NON. Nos finais do séc. XIV a correspondência entre etimologia e grafia deixa de ser sistemática; a progressiva adoção de grafias não etimológicas ao longo do séc. XV testemunha a tendência para a ditongação e aponta para uma inversão da tendência no último quartel de Quatrocentos (Cardeira 2005: 113ss). O Livro dos Mártires regista claramente esta convergência, por exemplo, na alternância entre formas como razom razam razaom razão, payxom payxam payxão. Em ambas, as terminações que correspondem à etimologia (-ONE) são maioritárias, mas as não etimológicas atingem quase $30 \%{ }^{10}$ e grafias como razão e payxão demonstram a presença do ditongo. Este dado aponta para uma atualização linguística à data da impressão. Por outro lado, sobrevivem ainda formas como multidõe ${ }^{11}$, que não encontramos no Flos Sanctorum nem no Cancioneiro Geral e que podem ser testemunhos de uma camada linguística mais antiga.

\section{GÉnero dos nOMES}

Também no género dos nomes encontramos vestígios dessa camada mais antiga no Livro dos Mártires: fim (9 ocorrências) é sempre do género feminino e linhagem é maioritariamente masculino ( 25 ocorrências no masculino e apenas 3 no feminino); os nomes femininos em -or ainda não registam a junção de $-a$ :

\section{Desque chego Galicano a Roma cõ sua hoste vêçedor}

Uos que sodes esposados huũ cõ eufrosina. e o outro cõ theadora virgeẽs muy sabedores que forõ cryadas de suũ.

No Flos Sanctorum, fim continua feminino, mas as 45 ocorrências de linhagem são já do género feminino; no Cancioneiro Geral já não se registam nomes femininos em -or sem a adjunção de - $a$; o género de fim oscila entre o feminino e o masculino, atingindo o masculino $29 \%$ e os nomes em -agem são, já, exclusivamente do género feminino (Cardeira 2012: 29). Curiosa é a comparação entre o Orto do Esposo e o Livro dos Mártires no que diz respeito ao género da forma linhagem: no Orto encontramos apenas 4 ocorrências no masculino (19\%), enquanto no Livro dos Mártires esta palavra é masculina em $89 \%$ dos $\operatorname{casos}^{12}$. Este dado aponta para um testemunho ainda anterior ao Orto.

\section{Demonstrativos: formas Reforçadas}

Uma caraterística do português antigo é a existência de formas reforçadas, a par das simples, bem com a variação do tipo esto/isto (sendo as variantes com e mais comuns) no sistema de demonstrativos (Mattos e Silva 2008: 377-378). A forma reforçada aqueste deixa de ocorrer nas fontes escritas a partir do séc. XVI (Martins 2016: 12-13). Podemos, portanto, esperar que o Livro dos Mártires, tal como o Flos Sanctorum, reflitam estas mudanças.

\footnotetext{
${ }^{10}$ Razõ tem 29 ocorrências, razõ 26, razon 1, rezõ 7 e rezom 3; razã 1, razam 1, razãa 1, rezã 6, rezam 15; razaom 1, razão 1 rezaõ 1. Paixõ regista 188 ocorrências, paixom 53, payxõ 19, payxom 20 e paxõ 1; paixã 37, paixam 21, payxã 18 e payxam 17; paixão 4, paixaõ 4, payxão 5 e payxaão 1.

${ }^{11}$ No Livro dos Mártires há 7 ocorrências de multidõe e 2 de multidoõe; 5 de multidõ e 3 de multidom. No Flos Sanctorum só ocorre multidom (1) e multidõ (8).

${ }^{12}$ Orto do Esposo: $\underline{\text { o linhagem }} 4$ ocorrências, a linhagem 21; Livro dos Mártires: $\underline{o}$ linhagem 25, a linhagem 3. Não foram contabilizadas as ocorrências em que o género não está expresso.
} 


\begin{tabular}{|l|r|r|r|r|l|}
\hline \multirow{2}{*}{ Formas simples } & \multicolumn{4}{|c|}{ oc. } & \multirow{2}{*}{ Formas reforçadas } \\
\cline { 2 - 5 } & \multicolumn{1}{|c|}{$\%$} & \multicolumn{2}{|c|}{$\mathbf{n}^{\circ}$} & \multicolumn{1}{c|}{$\%$} & \\
\hline este,-es, esta,-as & 67,98 & 431 & 203 & 32,01 & aqueste,-es, aquesta,-as \\
\hline esto & 48,68 & 148 & 156 & 51,31 & aquesto \\
\hline deste,-es, desta,-as & 67,02 & 126 & 62 & 32,97 & daqueste,-es, daquesta,-as \\
\hline desto & 10 & 2 & 18 & 90 & daquesto \\
\hline
\end{tabular}

Quadro 4. Formas simples e reforçadas dos demonstrativos (e respetivas contrações) no Livro dos Mártires

Como podemos ver no Quadro 4, predominam as simples nas formas variáveis e as reforçadas nas invariáveis. No conjunto, as formas reforçadas representam ainda $38 \%$ do total. Os resultados do Flos Sanctorum são bastante diferentes: as formas reforçadas são já residuais ou quase inexistentes, representando apenas $0.8 \%$ (Quadro 5).

\begin{tabular}{|l|r|r|r|r|l|}
\hline \multirow{2}{*}{ Formas simples } & \multicolumn{4}{|c|}{ oc. } & \multirow{2}{*}{ Formas reforçadas } \\
\cline { 2 - 5 } & \multicolumn{1}{c|}{$\%$} & \multicolumn{2}{|c|}{$\mathbf{n}^{\mathbf{0}}$} & \multicolumn{1}{c}{$\%$} & \\
\hline este,-es, esta,-as & 99,21 & 1259 & 10 & 0,78 & aqueste,-es, aquesta,-as \\
\hline esto & 98,83 & 507 & 6 & 1,16 & aquesto \\
\hline deste,-es, desta,-as & 100 & 244 & 0 & 0 & daqueste,-es, daquesta,-as \\
\hline desto & 98,48 & 65 & 1 & 1,51 & daquesto \\
\hline
\end{tabular}

Quadro 5. Formas simples e reforçadas dos demonstrativos (e respetivas contrações) no Flos Sanctorum

Acresce que no Livro dos Mártires não se registam formas do tipo isto, isso, enquanto no Flos Sanctorum ysto isto (46 ocorrências) alterna com esto (507) e ysso isso (31) com esso eso (74). Este é mais um dado que afasta a língua do Livro dos Mártires do início do séc. XVI.

\section{OUtROS INDICADORES}

Ainda no âmbito dos itens gramaticais, o Livro dos Mártires conserva os antigos locativos ala (55 ocorrências) e aca (13) ${ }^{13}$, bem como o pronome hu (248 ocorrências), formas já ausentes no Flos Sanctorum. Também o pronome oblíquo ende ${ }^{14}$ se encontra, como forma independente, no $\mathrm{Li}$ vro dos Mártires (23 ocorrências), enquanto o Flos Sanctorum apenas regista a forma porende. $\mathrm{O}$ advérbio adur, frequente no Orto do Esposo (aadur, 37), ainda ocorre no Livro dos Mártires (adur 6, aadur 1) mas já não no Flos Sanctorum; a forma aginha do Livro dos Mártires (54 ocorrências) já foi substituída por asinha no Flos Sanctorum (40 ocorrências). Paralelamente, ocorre a mudança do vb. trager para trazer (Machado 1989, s.v. trazer, regista a primeira atestação de trazer no séc. XIV). No Orto do Esposo ocorrem 186 formas com o radical trag- e 62 com traz-; no Livro dos Mártires encontramos 80 ocorrências de trag- e 9 de traz-; no Flos Sanctorum já se regista apenas traz- (171).

Uma caraterística que também aponta para uma camada linguística anterior à época do pos -incunábulo é a concordância do particípio passado com o objeto direto, aliada à preferência de haver como verbo auxiliar. Embora a concordância se verifique, esporadicamente, ainda no português clássico, a substituição de haver por ter ocorre durante o português médio (Martins 2016: 23).

ca bem cuydauã que era ja morto pola grãde fame que aueria sofrida.

hũ homẽ muy hõrado que auia nome querino. e que auia ja sofridas muytas feridas

Desque o emperador ouve lidas as cartas que o conde Ihe emuiou

\footnotetext{
${ }^{13}$ Também se registam, naturalmente, as formas aqui (100 ocorrências) e ali, alli, ally, aly (266).

${ }^{14}$ Sobre este pronome v. Teyssier (1981), que mostra a sua ausência, como forma independente, na língua literária do séc. XV. 
Quanto ao léxico (Quadro 6), algumas formas (verbos, nomes) que encontramos no Livro dos Mártires já não eram usuais no português quinhentista (Martins 2016: 27-28).

\begin{tabular}{|c|c|c|c|}
\hline Formas & Orto do Esposo & Livro dos Mártires & Flos Sanctorum \\
\hline aduzer & $\begin{array}{l}\text { aduz (5), aduzem (2), } \\
\text { aduzerõ, aduzido }\end{array}$ & $\begin{array}{l}\text { aduzer (3), aduzes, aduzeste, } \\
\text { aduzeras aduze, aduzido (4), } \\
\text { aduzida }\end{array}$ & - \\
\hline avir & $\begin{array}{l}\text { aueer (3), aueera (2), } \\
\text { aueesse (2), auenhã }\end{array}$ & auijr, aneeo, aueesse & - \\
\hline esmar, osmar & - & $\begin{array}{l}\text { esmo (4), esmas (3), esma, } \\
\text { esmades, esmou ( } 2 \text { ), esmasse, } \\
\text { esmado (2), esmadas, esmando } \\
\text { (3), osmas, osmamos, osmades } \\
\text { (2), osmes, osmãdo (2), osmado, } \\
\text { osmados, osmada }\end{array}$ & - \\
\hline guarir, garir & - & guarida, guarydos, garidos & guarido \\
\hline quitar; quite & - & $\begin{array}{l}\text { quito, quita, quitara; quite (3), } \\
\text { quites }\end{array}$ & $\begin{array}{l}\text { quitados; quite, } \\
\text { quites; quitamẽto }\end{array}$ \\
\hline sacar & - & sacar (3), sacarõ (2) & - \\
\hline seda & seeda (5) & seda (55), seeda (40) & - \\
\hline semelhar & semelhar (2) & $\begin{array}{l}\text { semelhar (2), semelha (21), } \\
\text { semelhas (5), semelhaes, } \\
\text { semelhamos (2), semelham (3), } \\
\text { semelhaua (48), semelhauam } \\
\text { (11), semelhou (5), semelharia, } \\
\text { semelhe }\end{array}$ & $\begin{array}{l}\text { semelhemos (2), } \\
\text { semelhãdo (2) }\end{array}$ \\
\hline $\begin{array}{l}\text { sia, siam, seve, severom } \\
\text { (imp. e perf. do vb. ser) }\end{array}$ & sija (2), sya & seue (24) & - \\
\hline vegada & - & vegada (11), vegadas (9) & - \\
\hline
\end{tabular}

Quadro 6. Léxico arcaizante-1

Muitas das formas presentes no Livro dos Mártires já não se encontram ou são significativamente menos frequentes no Flos Sanctorum.

\section{Conclusões}

O pos-incunábulo do Livro dos Mártires apresenta alguns traços que se harmonizam com o que sabemos sobre a língua do início do séc. XVI:

i. convergência em -ão das terminações nasais (razaom, payxão);

ii. ditongação no morfema número-pessoal (sereys) e no plural de formas paroxítonas de singular em -vel (perduraueis);

iii. ausência de formas átonas dos possessivos.

Estas caraterísticas deverão ser resultantes de atualização linguística, no momento da impressão. Contudo, a conservação de alguns traços de um estado de língua anterior afastam o pos-incunábulo do coevo Flos Sanctorum e aproximam-no do Orto do Esposo, de finais do séc. XIV ou início do XV (Quadro 7). 


\begin{tabular}{|l|r|r|r|}
\hline \multicolumn{1}{|c|}{ Traços distintivos-1 } & Orto do Esposo & Livro dos Mártires & Flos Sanctorum \\
\hline $\begin{array}{l}\text { Presença de }-d \text { - no morfema } \\
\text { número-pessoal }\end{array}$ & $100 \%$ & $91.3 \%$ & $2 \%$ \\
\hline Particípio passado em -udo & $38 \%$ & $9.5 \%$ & $1.4 \%$ \\
\hline
\end{tabular}

Quadro 7. Traços distintivos do português médio-1

Estas semelhanças com os dados do Orto do Esposo, e uma vez que no Leal Conselheiro as formas com - $d$ - são residuais e os particípios em -udo apenas atingem $7.8 \%$, apontam para um original de imprensa da primeira metade do séc. XV.

No entanto, algumas caraterísticas do Livro dos Mártires podem ser interpretadas como indícios da existência de um texto de base ainda mais antigo, já que se distanciam dos dados do Orto (Quadro 8).

\begin{tabular}{|l|r|r|r|}
\hline \multicolumn{1}{|c|}{ Traços distintivos-2 } & Orto do Esposo & Livro dos Mártires & Flos Sanctorum \\
\hline Formas reforçadas dos demonstrativos & $0.3 \%$ & $38 \%$ & $0.8 \%$ \\
\hline $\begin{array}{l}\text { Formas neutras metafonizadas isto, isso } \\
\text { (/esto, esso) }\end{array}$ & $1 \%$ & - & $11.7 \%$ \\
\hline linhagem do género masculino & $19 \%$ & $89 \%$ & - \\
\hline Vb. trazer (/trager) & $25 \%$ & $10 \%$ & $100 \%$ \\
\hline
\end{tabular}

Quadro 8. Traços distintivos do português médio-2

Acresce que algumas formas que já não ocorrem no Flos Sanctorum também não se encontram no Orto mas ainda se conservam no Livro dos Mártires (Quadro 9).

\begin{tabular}{|l|c|c|}
\hline \multicolumn{1}{|c|}{ Formas } & Orto do Esposo & Livro dos Mártires \\
\hline aca, ala & - & + \\
\hline esmar, osmar & - & + \\
\hline sacar & - & + \\
\hline vegada & - & + \\
\hline
\end{tabular}

Quadro 9. Léxico arcaizante-2

Trata-se de formas que estão também presentes na cópia quatrocentista da Demanda do Santo Graal, cópia conservadora que reflete bastante a língua do original duocentista (Martins 2016: 16-17 e 27-28). Poderemos, pois, tomá-las como testemunhos da língua da tradução, datável do período do português antigo, seguramente anterior ao final do séc. XIV.

Dos dados apresentados podemos concluir que a localização da tradução do terceiro livro da compilação de Bernardo de Brihuega na corte de D. Dinis, proposta por Cepeda, encontra agora fundamento, patente na conservação, no impresso, de traços arcaizantes da língua. Podemos ainda concluir que terá existido uma cópia integral desta tradução, feita no séc. XV, a qual foi usada como original de imprensa e de que o impresso conserva vários traços linguísticos. Dada a estreita relação entre a oficina de Valentim Fernandes e a família real, geralmente empenhada e comitente dos seus trabalhos, não será improvável que este manuscrito do séc. XV fosse aquele que possuía D. Duarte, copiado sobre manuscrito anterior e conservado na livraria régia até ao séc. $\mathrm{XVI}$. 
Estas paixões dos mártires ocuparam, portanto, lugar cativo na livraria da corte régia desde D. Dinis a D. Manuel, perfazendo duzentos anos de leitura que não poderão deixar de ser considerados no estudo da cultura e da espiritualidade dos leigos dos sécs. XIV-XVI.

Resta ainda retirar, deste trabalho, conclusões que interessam aos métodos filológicos. A edição semidiplomática é, reconhecidamente, aquela que melhor serve os interesses do historiador da língua, visto que o seu baixo grau de intervenção editorial (limitada ao desenvolvimento de abreviaturas e à separação e junção de palavras segundo a norma atual) é o que assegura o valor documental das formas atestadas. Por essa razão, corpora como o Corpus de Textos Antigos são fundamentais para o estudo da História da Língua. Mas saliente-se que a aplicação de critérios de edição semidiplomática não resulta numa representação automática do texto. Impõe-se a necessidade de análise linguística mesmo em edições com pequeno grau de intervenção editorial. Na verdade, foi a análise linguística e o estudo da estratificação documentada que conduziram à conservação, na edição deste texto, do til como marca de nasalidade em formas como camĩho, menĩo, pẽas.

\section{ReferênCIAs Biblográficas}

Askins, Arthur / Harvey Sharrer / Martha Schaffer et al., Bibliografia de Textos Antigos Galegos e Portugueses (BITAGAP), University of California: http://bancroft.berkeley.edu/philobiblon/bitagap_po.html [31/12/2017].

Bautista, Francisco (2014): "Bernardo de Brihuega y la colección hagiográfica del ms. BNE 10252", Zeitschrift fur romanische philologie 130/1, 71-104.

Bautista, Francisco (2015): "El final de la General Estoria", Revista de Filología Española 95/2, 251-278.

Bechara, Evanildo (1991): "As fases da língua portuguesa escrita", em Dieter Kremer (ed.), Actes du XVIII Congrès International de Linguistique et de Philologie Romanes, vol. III. Tübingen: Max Niemeyer Verlag, 68-76.

Beer, Rudolfo (1887): "Los cinco libros que compiló Bernardo de Brihuega por orden del rey don Alfonso el Sabio", Boletin de la Real Academia de la História 11, 366-369.

Cambraia, César Nardelli (2003): "Reconstruindo a tradição medieval portuguesa do Livro de Isaac. Estudo linguístico comparativo das versões existentes", em Fernando Sánchez Miret (coord.), Actas del XXIII Congreso Internacional de Lingüistica y Filología Románica, vol. IV. Tübingen: Max Niemeyer Verlag, 53-68.

Cardeira, Esperança (2005): Entre o Português Antigo e o Português Clássico. Lisboa: Imprensa Nacional-Casa da Moeda.

Cardeira, Esperança (2012): “Elementos para a periodização do português", em Roberval Teixeira e Silva et al. (orgs.), A formação de novas gerações de falantes de português no mundo. Macau: Universidade de Macau, 23-34.
Cardeira, Esperança (2013): “Do Português Médio ao Clássico: o Cancioneiro Geral de Garcia de Resende", em Emili Casanova Herrero / Cesareo Calvo Rigual (eds.), Actas del XXVI Congreso Internacional de Lingüística y de Filologia Románicas, vol. I. Berlin/Boston: De Gruyter, 576-587.

Cepeda, Isabel (1982-1989) (ed.): Vidas e Paixões dos Apóstolos, 2 vols. Lisboa: Instituto Nacional de Investigação Científica-Centro de Linguística da Universidade de Lisboa.

Cepeda, Isabel (1993): “Os 'Quarenta mártires de Sebaste'. Um testemunho manuscrito do século XV em português", Theologica 28/2, 507-514.

Dias, João José Alves (1995): "Os primeiros impressores alemães em Portugal", em João José Alves Dias (coord.), No Centenário da Vita Christi. Os primeiros impressores alemães em Portugal. Lisboa: Instituto da Biblioteca Nacional de Lisboa, 15-27.

Díaz y Díaz, Manuel C. (1962): "La obra de Bernardo de Brihuega, colaborador de Alfonso X", Strenae. Estudios de Filología e Historia dedicados al profesor Manuel García Blanco. Salamanca: Universidad de Salamanca, 145-61.

Ferreiro, Manuel (2008):“Edición e historia da lingua: Sobre a representación da nasalidade no trobadorismo profano galego-portugués e as formas irmana e afíns", em Manuel Ferreiro / Carlos Paulo Martínez Pereiro / Laura Tato Fontaíña (eds.), A edición da Poesía Trobadoresca en Galiza. A Coruña: Bahía Edicións, 77-96.

Jüsten, Helga (2006): Incunábulos e Post-Incunábulos Portugueses (ca. 1488-1518): em redor do material tipográfico dos impressores portugueses. Universidade Nova de Lisboa. Tese de doutoramento.

Livro dos conselhos de el-rei D. Duarte (livro da cartuxa) (1982). Edição diplomática, transcrição de João José Alves Dias. Lisboa: Estampa. 
Machado, José Pedro (19895): Dicionário Etimológico da Língua Portuguesa, 5 vols.. Lisboa: Horizonte.

Maia, Clarinda de Azevedo (1986): História do Galego-Português. Coimbra: Instituto Nacional de Investigação Científica.

Martins, Ana Maria (2016):"Introdução: O português numa perspetiva diacrónica e comparativa", em Ana Maria Martins / Ernestina Carrilho (eds.), Manual de Linguística Portuguesa. Berlin/Boston: De Gruyter, 1-39.

Martins, Mário (1961):"A legenda dos Santos Mártires e o Flos Sanctorum de 1513", Brotéria 72, 155-165.

Martins, Mário (1980ª): "As omissões do Livro e Legenda que fala de todolos feitos e paixões dos santos mártires", Estudos de Cultura Medieval, vol. II. Lisboa: Brotéria, 121-130 [1ª ed. Braga: Magnificat, 1972].

Martins, Mário (1980²b): "Bernardo de Brihuega, compilador do Livro e Legenda que fala de todolos feitos e paixões dos santos mártires", Estudos de Cultura Medieval, vol. II. Lisboa: Brotéria, 105-119 [1 a ed. Braga: Magnificat, 1972].
Mattos e Silva, Rosa Virgínia (2008): O Português Arcaico. Uma Aproximação, vol. I: Léxico e Morfologia. Lisboa: Imprensa Nacional-Casa da Moeda.

Sobral, Cristina (2000): Adições Portuguesas no Flos Sanctorum de 1513 - estudo e edição crítica. Universidade de Lisboa. Tese de Doutoramento.

Sonsino, Ana, Marta Cruz / Cristina Sobral: edição semidiplomática de Livro dos Mártires em Corpus de Textos Antigos, Centro de Linguística da Universidade de Lisboa: http://alfclul.clul.ul.pt/ teitok/cta/index.php?action $=$ file\&id $=2265 . x \mathrm{ml}$ [17-02-2018].

Teyssier, Paul (1981): "Le systéme des déictiques spatiaux en portugais aux $\mathrm{XVl}^{e}, \mathrm{XV}^{\mathrm{e}}$ et $\mathrm{XVl} \mathrm{e}^{\mathrm{e}}$ siècles", Cahiers de linguistique hispanique médiévale 6, 5-39.

Vasconcellos, José Leite de (1906): "Fórmas verbaes arcaicas no Leal Conselheiro de el-rei D. Duarte", Mélanges Chabaneau, Romanische Forschungen 23, 175-178. 
USC 